\title{
O liberalismo e a definição bobbiana de democracia: \\ elementos para uma análise crítica
}

Liberalism and the Bobbian definition of democracy: elements for a critical analysis

Norberto Bobbio é um autor consagrado no campo da teoria democrática. Numerosos são seus seguidores e muito escassos seus detratores. Para as correntes dominantes, Bobbio é frequente objeto de laudatórios comentários e citações. Quadro análogo se verifica, também e curiosamente, entre muitos defensores de uma democracia alternativa ou mais progressista. Consideramos, porém, que a construção de uma concepção democrática autenticamente contra-hegemônica deveria incluir, entre suas tarefas iniludíveis, o questionamento às teses do renomado intelectual de Turim - teses, em muitos casos, impregnadas de um viés mais ou menos elitista e conservador.

É assim, então, que, situados na contramão da orientação majoritária, buscaremos analisar criticamente alguns dos principais elementos constitutivos da definição bobbiana da democracia. Começaremos por discutir a problemática relação que Bobbio estabelece entre a democracia e o liberalismo, por entender que tal discussão nos oferecerá uma boa base para realizar, nas páginas seguintes, um exame mais acurado das ambiguidades de Bobbio frente ao fenômeno democrático e de seus temores frente a qualquer possibilidade de um envolvimento mais ativo das grandes massas populares na vida pública. Consequentemente, dividimos o texto em quatro seções: As relações

\footnotetext{
É professor de Ciência Política na Universidade Federal do Rio Grande do Norte (Natal, RN, Brasil). E-mail: gvitullo@hotmail.com

** É doutorando no Programa de Pós-graduação em Ciências Sociais na Universidade Federal do Rio Grande do Norte (Natal, RN, Brasil). E-mail: davidegiacobboscavo@hotmail.com
} 
entre o liberalismo e a democracia no pensamento de Norberto Bobbio; A defesa da democracia representativa e a condenação da democracia direta; "O excesso de democracia" e a filosofia da resignação; e Considerações finais.

\section{As relações entre o liberalismo e a democracia no pensamento de Norberto Bobbio}

No que diz respeito às relações entre o liberalismo e a democracia, há na obra de Norberto Bobbio uma tendência a assumir ambos os conceitos como estreita e auspiciosamente interligados ${ }^{1}$. Tal tendência o situa, dentro do campo da ciência política, como um dos grandes sistematizadores e defensores da "fórmula democrático-liberal", apresentada como um modelo racional de ordem social, capaz de preservar a livre existência do ser humano na sociedade de massas. Para o nosso autor, o que caracterizaria o regime político moderno como democrático seria a garantia dos direitos individuais. Desse ângulo, tal regime configuraria o natural prosseguimento do Estado liberal, acolhendo, em sua própria estrutura, os clássicos direitos de liberdade civis e políticos habitualmente associados ao pensamento liberal. O liberalismo, tido por Bobbio (1997, p. 219) como superior historicamente às outras formas políticas, opera como fundamento e condição necessária do governo democrático moderno. Para o intelectual italiano,

o Estado liberal é o pressuposto não só histórico, mas também jurídico do Estado democrático. Estado liberal e Estado democrático são interdependentes em dois modos: na direção que vai do liberalismo à democracia, no sentido de que são necessárias certas liberdades para o exercício correto do poder democrático, e na direção oposta que vai da democracia ao liberalismo, no sentido de que é necessário o poder democrático para garantir a existência e a persistência das liberdades fundamentais. Em outras palavras: é pouco provável que um estado não liberal possa assegurar um correto funcionamento da democracia e de outra parte é pouco provável que um estado não democrático seja capaz de garantir as liberdades fundamentais. A prova histórica desta interdependência está no fato de que Estado liberal e Estado democrático, quando caem, caem juntos (Bobbio, 2006b, p. 32-33).

Dizemos "tendência", pois há passagens da obra de Bobbio em que se observam certas nuances, ao considerar que a relação entre o liberalismo e a democracia não é lineal nem historicamente foi tão pacífica. Não obstante isso, a interpretação que predomina nos seus escritos é a que sublinha a continuidade histórica entre ambos, interpretação que aqui haveremos de analisar criticamente. 
$\mathrm{Na}$ interpretação de Bobbio, a democracia moderna seria o triunfo do indivíduo e consequência histórica do liberalismo. Assim sendo, liberalismo e democracia repousariam, ambos, sobre uma concepção individualista de sociedade, considerando os direitos da pessoa - a liberdade de opinião, de expressão, de reunião, de associação - como de origem liberal, ficando cristalizados e garantidos na democracia moderna, com o reconhecimento constitucional de direitos "invioláveis” do indivíduo.

A democracia nasceu de uma concepção individualista da sociedade, isto é, da concepção para a qual - contrariamente à concepção orgânica, dominante na idade antiga e na idade média, segundo a qual o todo precede as partes - a sociedade, qualquer forma de sociedade, e especialmente a sociedade política, é um produto artificial da vontade dos indivíduos (Bobbio, 2006b, p. 34).

$\mathrm{O}$ assinalado até aqui pressupõe ter que aceitar que esses direitos estejam necessariamente associados, como habitualmente se faz, ao patrimônio político e categorial do liberalismo. Significa ter que aceitar, também, a caracterização que o intelectual italiano faz de figuras como Locke, Tocqueville, Bentham ou Stuart Mill, os quais define como expoentes do "pensamento liberal e democrático" (Bobbio, 2006b, p. 34)2. Bobbio, nesses assuntos, faz parte de uma tradição solidamente estabelecida que leva a creditar ao liberalismo - e, junto com este, à burguesia - os louros exclusivos pela consagração dos direitos e liberdades de pensamento, de expressão, de reunião e de associação e que considera a defesa de tais direitos e liberdades como sendo a quintessência do Estado liberal. Caberia se interrogar se isso de fato condiz com a verdade histórica. Não deveríamos questionar essa associação tão tranquilamente aceita? Por que concordar com a tese de que são os liberais os únicos e verdadeiros intérpretes da causa da liberdade e dos direitos recém arrolados? Até que ponto esses direitos são obra do liberalismo? Até quando tributaremos gratidão aos liberais por direitos que nem sempre eles impulsionaram ou de cujo avanço não são exclusivos responsáveis? Podemos lembrar, a mero título

Curiosamente e incorrendo em contradição com o que acabamos de mencionar, em outro dos textos que compõem a obra "O futuro da democracia", Bobbio faz referência a Locke, Kant, Humboldt e Adam Smith e indica que nenhum "dos primeiros propagadores do liberalismo pode ser arrolado entre os escritores democratas" (Bobbio, 2006b, p. 136). Para quem quiser contar com uma base mais firme a partir da qual caracterizar esses e outros ícones do pensamento liberal, vale a pena consultar o excelente livro de Domenico Losurdo (2006), "Contra-história do liberalismo". 
ilustrativo, os casos do direito ao sufrágio ou do direito de livre associação e dos fortes obstáculos que os liberais interpuseram à sua ampliação para as classes subalternas e, portanto, a seu processo de universalização ${ }^{3}$. Isso é algo que o próprio Bobbio de alguma forma reconhece quando, por exemplo, atribui aos niveladores o papel precursor na luta pelo voto universal (Bobbio, 2006a, p. 50), em confronto com as forças liberais, as quais por muito tempo teimaram em negar essa ampliação dos direitos políticos ${ }^{4}$.

Mas voltemos à questão central que nos ocupa nesta seção. De forma taxativa, em "Liberalismo e democracia", Bobbio afirma que "hoje Estados liberais não-democráticos não seriam mais concebíveis, nem Estados democráticos que não fossem também liberais" (Bobbio, 2006a, p. 43). Afirmação de calibre semelhante encontramos algumas páginas mais à frente, nesse mesmo livro, quando ele sentencia que "a combinação entre liberalismo e democracia não apenas é possível, como também necessária” (Bobbio, 2006a, p. 47). Tais asseverações levam a bloquear toda possibilidade de sequer pensar numa democracia "mais democrática" - uma democracia que afirme e expanda direitos e liberdades, superando a tradição liberal. As considerações de Bobbio nessa matéria constituem um bom exemplo daquilo que Carlos Estevam Martins define como a rotunda hegemonia ideológica alcançada pelos liberais ${ }^{5}$. Nesse contexto, em que o pensamento liberal se arroga um lugar de privilégio no âmbito da defesa das liberdades, empurrando as demais correntes para o campo autoritário, não resta muito espaço para a luta por uma democracia pós-liberal ou não liberal.

Bernard de Mandeville, ao descrever as primeiras tentativas dos trabalhadores de se auto-organizarem, assinalava:"Fui informado, por pessoas dignas de confiança, que alguns desses lacaios chegaram a tal grau de insolência que se reuniram em sociedade e fizeram leis pelas quais se obrigam a não prestarem serviço por soma inferior ao que estabeleceram entre si, a não carregar malas, embrulhos ou pacotes acima de certo peso, fixado em duas ou três libras, e que se impuseram uma série de outras regras diretamente opostas ao interesse daqueles a quem prestam serviço e, ao mesmo tempo, contrárias à finalidade para a qual foram contratados" (Maneville apud Losurdo, 1996, p. 6). Para outros exemplos referentes a esse tópico, sugerimos consultar Vitullo (2009).

4 Num próximo trabalho, tentaremos desenvolver e aprofundar essa linha argumentativa, de modo a seguir a sugestão de Carlos Estevam Martins (2003, p. 625), quando alerta para a necessidade da "compreensão da democracia como uma possibilidade à parte, cuja identidade não se confunde com a do liberalismo" e até, agregaríamos, é em muitos aspectos antagônica ao liberalismo.

"A hegemonia liberal manifesta-se de diversas maneiras. Uma delas consiste no fato de que, hoje em dia, tentar ser antiliberal tornou-se tarefa difícil e até mesmo perigosa, capaz de pôr em risco sólidas reputações. Quem não é ou não quer ser liberal, quem tenta combater o liberalismo em nome de alguma concepção alternativa, enfrenta um terreno minado, repleto de armadilhas que induzem ao erro ou expõem os incautos a críticas imerecidas" (Martins, 2003, p. 619). 
Todavia, vale insistir: essa relação de suposta continuidade temporal e conceitual deve ser rediscutida. Aqueles que advogamos por uma democracia autenticamente popular não deveríamos aceitar, passivamente, o retrato que os ideólogos liberais fazem da história do pensamento democrático moderno e sua "evolução". Pois, como bem aponta Domenico Losurdo:

Não resiste à investigação histórica o mito, caro a Bobbio, do desenvolvimento espontâneo do liberalismo em direção à democracia. É um dado de fato que precisamente os países com uma tradição liberal mais consolidada acumularam um considerável atraso histórico no próprio terreno da emancipação política (Losurdo, 2004, p. 51).

Resta evidente que essa forçada relação de complementariedade entre o liberalismo e a democracia tem seu preço; preço, por sinal, bastante elevado. Bobbio reconhece que tanto a compatibilização conceitual entre o liberalismo e a democracia quanto a compreensão desta como desenvolvimento natural ${ }^{6}$ e auspicioso do Estado liberal só são possíveis "se [a democracia for] tomada não pelo lado de seu ideal igualitário, mas pelo lado de sua fórmula política, que é, como se viu, a soberania popular" (Bobbio, 2006a, p. 42-43). Cumpre esclarecer, todavia, que a invocação da soberania popular não passa de retórica vazia, pois o próprio Bobbio explica que o liberalismo dos modernos e a democracia dos antigos foram, com frequência, antitéticos, na medida em que os liberais historicamente exprimiram uma profunda desconfiança para com toda forma de governo popular, o que os motivou a defender severas restrições no exercício do direito ao sufrágio. Além disso, para Bobbio (2006a, p. 38), a associação entre ambos os termos implica o dever de interpretar a palavra democracia no seu sentido jurídico-procedimental, e não no sentido ético.

No parágrafo acima, as expressões que merecem destaque são "fórmula política" e "sentido jurídico-procedimental", elementos definidores, para

A escolha da palavra "natural" não é, certamente, nada inocente. Ela aparece de maneira reiterada nos textos de Bobbio quando este faz referência à suposta continuidade que existiria entre o liberalismo e a democracia, tanto ao oferecer seus próprios argumentos quanto quando comenta as ideias de alguns dos clássicos do liberalismo. Eis alguns exemplos: "natural prosseguimento" (Bobbio, 2006a, p. 37), "natural desenvolvimento" (Bobbio, 2006a, p. 42), "democracia como desenvolvimento natural e consequente dos princípios liberais" (Bobbio, 2006a, p. 62), "democracia representativa [...] prosseguimento natural de um Estado desejoso de assegurar aos seus cidadãos o máximo de liberdade" (Bobbio, 2006a, p. 68). A intenção é clara: promover a naturalização dos fenômenos sociais e assim tentar convencer o leitor da pertinência da sua linha interpretativa. 
Bobbio, do processo democrático. Processo democrático este que consiste meramente em completar o clássico Estado liberal com as liberdades políticas (Bobbio, 2006a, p. 84). Já o ideal igualitário é, sem muitas explicações da parte do nosso autor, liminarmente expulso do panteão democrático. Eis, portanto, a chave do roteiro interpretativo e da proposta política defendidos por Bobbio: o abandono puro e simples de todo conteúdo substantivo, de toda e qualquer aspiração igualitária, de toda e qualquer associação da democracia com ideais de justiça e de transformação social. A democracia moderna, para Bobbio, diz respeito, apenas, a uma questão de procedimentos. É precisamente sobre essa definição que iremos nos debruçar na seção a seguir.

\section{A defesa da democracia representativa e a condenação da democracia direta}

É assim, então, que para nosso autor a democracia é meramente uma "forma de governo caracterizada por um conjunto de regras que permitem a mudança dos governantes sem necessidade de usar a violência” (Bobbio, 1996, p. 233), forma que possibilita "a livre e pacífica convivência dos indivíduos numa sociedade" (Bobbio, 1998, p. 82). A democracia seria nada mais que "um mecanismo para eleger e autorizar governos", possibilitando a alternância das elites no poder (Bobbio, 1955, p. 175; 2006b). Não é um ideal utópico, mas uma prosaica técnica para a organização do Estado, centrada em "estabelecer não já o que se deve decidir, mas somente o quem precisa decidir e como" (Bobbio, 1987, p. 381) ${ }^{7}$.

A democracia fica reduzida a uma simples técnica de autorreprodução das relações de poder e de separação entre representantes e representados via mecanismos de representação, ou via "regras do jogo", como gosta de defini-las o próprio Bobbio. Isso dá lugar a uma teoria democrática profundamente pautada pelas noções de governabilidade e estabilidade, em oposição a qualquer proposta que venha a desafiar o status quo. Dá lugar a uma concepção procedimental de democracia de claro caráter elitista, que transforma o conceito originário de democracia em uma técnica constituída

Consideramos que essa é a definição que acaba predominando no pensamento bobbiano, neutralizando outra definição, a definição ética, presente na primeira metade da sua extensa trajetória acadêmica. Para mais esclarecimentos sobre as mudanças experimentadas por Bobbio na teorização da questão democrática, recomenda-se consultar o interessante texto de Brandão (2006). 
por normas que visam garantir a eleição rotativa das lideranças políticas; lideranças que desempenhariam um papel comparável aos dos empresários

cujo lucro é o poder, cujo poder se mede por votos, cujos votos dependem da sua capacidade de satisfazer interesses de eleitores e cuja capacidade de responder às solicitações dos eleitores depende dos recursos públicos de que pode dispor. Ao interesse do cidadão eleitor de obter favores do Estado corresponde o interesse do político eleito ou a ser eleito de concedê-los. Entre um e outro estabelece-se uma perfeita relação de do ut des: um, através do consentimento confere poder, o outro, através do poder recebido, distribui vantagens ou elimina desvantagens (Bobbio, 2006b, p. 138) ${ }^{8}$.

Cabe esclarecer que longe de nós está querer defender a tese de que as regras do jogo não sejam relevantes e que devam ser desconsideradas. Não é essa a nossa posição. Seguimos aqui os ensinamentos de Rosa Luxemburgo (1991), que com sua habitual lucidez destacara a importância da esfera institucional para o processo revolucionário e para a própria sociedade futura. Importância esta, todavia, que não a levava a pensar, ingenuamente, que a democracia pudesse se limitar apenas a um conjunto de regras de procedimento ${ }^{9}$. Muito longe disso, pois, para a revolucionária polonesa, a democracia significava um projeto de autoemancipação social, uma democracia que não só não entra em contradição com o projeto do socialismo revolucionário mas que encontra com este uma estreita inter-relação. Para Rosa Luxemburgo, não há como separar democracia, socialismo e revolução; trata-se de uma posição evidentemente muito distante do caminho trilhado por Norberto Bobbio e dos estreitos horizontes políticos que orientam sua reflexão intelectual.

E, especificamente no que diz respeito à democracia representativa, Bobbio não vê que haja incompatibilidade entre esta e o poder popular. Referindo-se aos Federalistas e aos constituintes franceses, considera que estes “[...] não pensavam realmente que instituindo uma democracia representativa

\footnotetext{
8 Mesmo com certos reparos, Bobbio termina incorporando a analogia mercantil ao marco teórico que utiliza para definir o fenômeno democrático e tecendo elogios à - para ele - ideia "iluminante" de Max Weber - depois desenvolvida por Schumpeter - de que o papel do líder político pode ser equiparado ao papel do empresário capitalista (Bobbio, 2006b, p. 138).

9 "Nunca fomos idólatras da democracia formal só pode significar uma coisa: sempre fizemos distinção entre o núcleo social e a forma política da democracia burguesa, sempre desvendamos o áspero núcleo de desigualdade e de servidão sociais escondido sob o doce invólucro da igualdade e da liberdade formais - não para rejeitá-las, mas para incitar a classe operária a não se contentar com o invólucro, incitá-la a conquistar o poder político para preenchê-lo com um conteúdo social novo" (Luxemburgo, 1991, p. 95-96)
} 
acabariam por enfraquecer o governo popular” (Bobbio, 2006a, p. 34), quando na verdade o objetivo central perseguido pelos pais da Constituição estadunidense com o desenvolvimento do governo representativo era, sim, precisamente, o de enfraquecer ou neutralizar o poder político das camadas populares. Leia-se bem: utilizamos a expressão "governo representativo" e não "democracia representativa”, como faz erroneamente Bobbio (2006a, p. 34), pois os Federalistas eram explicitamente contrários ao regime democrático e defensores de um governo representativo ou republicano. Só várias décadas depois será instalada no debate público a fórmula "democracia representativa", entendida muito mais como sinônimo de "governo representativo" no sentido atribuído pelos Federalistas do que como sinônimo de poder popular. Disso deriva a necessidade de questionar também a argumentação de Norberto Bobbio quando alega que "tanto a democracia direta quanto a indireta descendem do mesmo princípio da soberania popular, apesar de se distinguirem pelas modalidades e pelas formas com que essa soberania é exercida" (Bobbio, 2006a, p. 34).

Vale ressaltar que Norberto Bobbio desempenhou, ao longo do século XX, um papel importante na difusão e legitimação dessa fórmula política, em que o adjetivo tem uma importância maior que o substantivo. Compreende-se, assim, por que para o intelectual turinense resulte importante preservar a distância entre os representados e os representantes, permitindo a estes últimos a tutela dos interesses gerais do Estado, superiores aos interesses dos eleitores, gozando de um mandato não revogável, acima dos interesses terrenos da população. Compreende-se, de igual forma, que para Bobbio (2006b, p. 36) a principal característica da democracia moderna seja a representação política, isto é, um tipo de vínculo segundo o qual o representante, sendo chamado a perseguir os interesses da nação, não pode estar sujeito a um mandato imperativo.

O nosso autor defende, como diz Negri (1989), uma democracia centrada nas liberdades dos indivíduos, que não pode ser entendida em seu sentido originário, como garantia de direitos coletivos e incentivo à participação direta da população nas políticas públicas e a expansão da sociedade civil no Estado. Segundo Bobbio, a participação direta é apenas uma utopia, não sendo realizável nas sociedades de massa, podendo-se tornar uma perigosa máquina de construção do totalitarismo (Negri, 1989). Para Bobbio a participação popular direta dos cidadãos seria viável só 
numa pequena comunidade, como era a do modelo clássico por excelência, a Atenas do $\mathrm{V}$ e do IV séculos, quando os cidadãos não passavam de poucos milhares e a sua assembleia, considerando-se os ausentes por motivo de força maior ou por livre e espontânea vontade, reunia-se com todos juntos no lugar estabelecido (Bobbio, 2006b, p. 65).

Ainda com relação a esse tema, Bobbio assinala:

É evidente que, se por democracia direta se entende literalmente a participação de todos os cidadãos em todas as decisões a eles pertinentes, a proposta é insensata. Que todos decidam sobre tudo em sociedades sempre mais complexas como são as modernas sociedades industriais é algo materialmente impossível. E também não é desejável humanamente, isto é, do ponto de vista do desenvolvimento ético e intelectual da humanidade. Em seus escritos de juventude Marx havia indicado o homem total como meta do desenvolvimento civil da humanidade. Mas o indivíduo rousseauniano conclamado a participar da manhã à noite para exercer os seus deveres de cidadão não seria o homem total, mas o cidadão total [...]. E, bem vistas as coisas, o cidadão total nada mais é que a outra face igualmente ameaçadora do Estado total. Não por acaso a democracia rousseauniana foi frequentemente interpretada como democracia totalitária em polêmica com a democracia liberal (Bobbio, 2006b, p. 54-55).

Bobbio retoma, portanto, o argumento weberiano que visa justificar a impossibilidade da participação direta dos cidadãos na vida pública. Bobbio procura demonstrar a inevitabilidade da perda de controle sobre o processo de decisão política e econômica que vem experimentando o cidadão comum em favor da organização burocrática, fruto do surgimento e o desenvolvimento do Estado moderno. E, na mesma linha argumentativa de Weber, Bobbio expressa a necessidade de que sejam os líderes políticos os que controlem o aparelho burocrático, na medida em que o pessoal administrativo não detém as informações necessárias para execução de políticas complexas, sendo incapaz de indicar as soluções necessárias nas diversas situações que se apresentam.

Frente à complexidade e ao avanço do processo burocratizador, no pensamento bobbiano não cabe a possibilidade de uma democracia mais radical que permita à população exercer o controle sobre dito processo. O controle caberá aos líderes políticos, escolhidos periodicamente pela população. Mas será que essa resposta, a resposta elitista, é a única possível? Por que diante do aumento da complexidade, não haveria de se pensar que se torna cada vez mais necessária a expansão da própria democracia, multiplicando 
os espaços para a efetiva participação popular? Não haveria assim maiores chances de ouvir mais vozes e de contemplar um maior leque de interesses?

Ian Budge (1993) argumenta, acertadamente, que a tentativa de utilizar a teoria da eleição social como arma contra a democracia direta pode derivar para uma argumentação contra a própria democracia, mais do que contra alguma das formas particulares que esta venha a assumir. Em igual sentido se manifesta James Bohman (1996), que explica que os discursos acerca do caráter inevitável da complexidade primeiro rejeitam a possibilidade de participação, depois questionam a possibilidade de deliberação, depois colocam em xeque a viabilidade da representação e finalmente acabam exigindo a liquidação da própria democracia. Não é o itinerário desejado por Bobbio, claro; contudo, e sem querê-lo, ele termina oferecendo elementos que podem legitimar esses discursos. Para Bohman, não haveria uma antinomia funcional entre incrementar a democracia e, por sua vez, manter a complexidade. Ao contrário, muitos dos mesmos mecanismos políticos que reduzem a complexidade também reduziriam a própria democracia. Assim, para esse autor, a complexidade facilitaria a deliberação pública e asseguraria a possibilidade de decisões livres e contingentes, motivo que justifica o aprofundamento de instâncias reais de participação política direta e autônoma.

No passado, a grande preocupação dos liberais estava centrada no risco de tirania da maioria. Hoje o fantasma que persegue os liberais é o da ingovernabilidade, definida nas palavras de Bobbio como a "incapacidade dos governos democráticos de dominarem convenientemente os conflitos de uma sociedade complexa: um alvo de sinal oposto, não o excesso, mas o defeito do poder" (Bobbio, 2006a, p. 92). Não nos convence a explicação bobbiana: será que estamos realmente frente a um alvo de sinal oposto? Não se trata, na sua essência, da mesma ameaça: a ameaça do poder popular? No primeiro caso o poder popular no governo, no segundo o poder popular no seio da sociedade, demandando ao governo o que este supostamente não poderia dar. É oportuno lembrarmos o Relatório da Comissão Trilateral, em que Crozier, Huntington e Watanuki (1975) faziam um claro apelo em prol de uma redução da democracia em nome da preservação da estabilidade política e das próprias instituições da democracia representativa ${ }^{10}$, o que na

10 Um autor que nestes últimos anos vem insistindo com esse tema é Fareed Zakaria (1997, 2003), que goza de grande prestígio na ciência política dominante. Para mais detalhes sobre esse tema, sugere-se consultar Vitullo (2007). 
prática significava uma luta por menos, e não mais, poder popular. Tirania da maioria, ingovernabilidade, dois nomes, então, que buscam conjurar e neutralizar a força política das classes subalternas. Eis, portanto, uma clara expressão do caráter elitista, antidemocrático e conservador que orienta a prédica das correntes hegemônicas na ciência política contemporânea, das quais infelizmente Norberto Bobbio parece não estar tão distante, conforme observaremos na seção a seguir.

\section{"O excesso de democracia" e a filosofia da resignação}

Depois da terrível experiência do fascismo, Bobbio prefere atuar nos quadros da ordem da democracia capitalista realmente existente ${ }^{11}$, optando pela democracia liberal frente às ilusões alternativas e aos projetos sociais transformadores. Entendemos perfeitamente os medos que perseguiram Bobbio ao longo de sua vida quase centenária, porém não temos como partilhar suas tímidas escolhas políticas e teóricas.

Segundo o renomado jurista e cientista político italiano, a democracia moderna, apesar das limitações e das numerosas "promessas não cumpridas" - como a revanche dos interesses, a permanência das oligarquias, a participação interrompida, os poderes ocultos, o cidadão não educado, a tecnocracia - é a melhor forma de governo possível, respondendo aos "requisitos mínimos" e apresentando "deficiências" de maneira alguma realizáveis na sociedade de massa, sendo limitações das quais não há como escapar, "deficiências necessárias da democracia representativa estabelecida" (Anderson, 1989, p. 32; Bobbio, 2006b).

Frente aos limites da democracia representativa, diz Bobbio, os indivíduos precisam adaptar-se, aceitando no lugar da utopia uma democracia procedimentalista, um conjunto de regras para a tomada de decisões, um arranjo institucional para eleger lideranças, "um conjunto de regras (primárias ou fundamentais) que estabelecem quem está autorizado a tomar decisões coletivas e com quais procedimentos" (Bobbio, 2006b, p. 30, grifos no original). E ainda assinala:

"Para Atilio Boron (2001), deveríamos falar em "capitalismo democrático"e não em "democracia capitalista". Não concordamos com o cientista político argentino, pois a questão realmente substantiva, aqui, é o adjetivo. Como diz Losurdo (2004, p. 326) ao se referir a outro par conceitual, o "cesarismo democrático", o adjetivo apresenta o risco de funcionar como elemento de legitimação. No nosso caso, legitimação do sistema do capital, algo que obviamente não está entre os objetivos defendidos por Boron. 
Todo o resto está entre a construção de castelos no ar e a agitação pela agitação destinada a fazer aumentar, a curto e a longo prazo, as frustrações. É pouco. Mas mesmo este pouco é tão incerto que buscar outra coisa significa colocar-se mais uma vez na estrada das expectativas destinadas à desilusão (Bobbio, 2006b, p. 95).

Mas, para não pecar de pessimista, diante do quadro desolador pintado acima, o turinense ensaia algum modo de consolação, quando indica que

as promessas não cumpridas e os obstáculos não previstos de que me ocupei não foram suficientes para "transformar" os regimes democráticos em regimes autocráticos A diferença substancial entre uns e outros permaneceu. O conteúdo mínimo do Estado democrático não encolheu: a garantia dos principais direitos de liberdade, existência de vários partidos em concorrência entre si, eleições periódicas e sufrágio universal, decisões coletivas ou concordadas (nas democracias consociativas ou no sistema neocorporativo) ou tomadas com base no princípio da maioria, e de qualquer modo sempre após um livre debate entre as partes ou entre os aliados de uma coalizão de governo (Bobbio, 2006b, p. 50).

Assim, a teoria bobbiana da democracia está concentrada na garantia dos direitos individuais, que na sua leitura do liberalismo são "expressão da personalidade individual, mesmo se o desenvolvimento da personalidade mais rica e dotada puder se afirmar em detrimento do desenvolvimento da personalidade mais pobre e menos dotada" (Bobbio, 2006a, p. 39). Uma democracia que pode, sim, ser melhorada, ampliando a representação e as possibilidades de voto, aumentando "os espaços nos quais podem exercer este direito" (Bobbio, 2006b, p. 40), porém sempre mantendo claros limites à participação popular e tendo a representação eleitoral como garantia contra o poder da maioria popular.

O pensamento político bobbiano responde com bastante fidelidade à interpretação webero-kelseniana-schumpeteriana da prática democrática, tida como um modelo racional e legal, cujo marco inicial e fundamental é a norma enquanto limite frente à radicalidade de qualquer impulso utópico, garantindo a racionalidade no lugar das ilusões que levem à morte da democracia e, consequentemente, à vigência do totalitarismo. Nas suas palavras: "[J]amais esqueci o ensinamento de Karl Popper segundo o qual o que distingue essencialmente um governo democrático de um não-democrático é que apenas no primeiro os cidadãos podem livrar-se de seus governantes sem derramamento de sangue" (Bobbio, 2006b, p. 51). 
É por isso que, para Bobbio, os altos índices de apatia política não configuram, necessariamente, um problema a ser combatido. Ao contrário, confirmando seu desconforto com a participação ativa das massas populares na política, o cientista político italiano qualifica a "apatia política" como um elemento positivo e saudável, sendo um mínimo "custo que se deve pagar pelo empenho de alguns poucos". Abertamente ele, num dos textos que compõem O futuro da democracia, declara:

A abstenção do voto aumentou, mas até agora de maneira não preocupante; de resto, a apatia política não é de forma alguma um sintoma de crise de um sistema democrático, mas, como habitualmente se observa, um sinal da sua perfeita saúde: basta interpretar a apatia política não como recusa ao sistema mas como benévola indiferença (Bobbio, 2006b, p. 82).

E, para reforçar ainda mais seu posicionamento e não deixar dúvidas sobre seus temores frente à possibilidade de uma participação mais intensa das massas populares na vida pública, Bobbio desfere uma das frases mais marcantes de todo esse livro: "Nada ameaça mais matar a democracia que o excesso de democracia” (Bobbio, 2006b, p. 39). Tal frase constitui toda uma declaração de princípios em favor de um projeto extremadamente limitado de democracia, um projeto que oferece ingredientes muito mais identificados com a tradição liberal do que com a tradição democrática. Um projeto para o qual a representação opera como uma útil ferramenta destinada a limitar o "excesso de participação" e garantir as necessárias mediações normativas e os procedimentos que impeçam a intervenção direta das massas na esfera política ou na vida pública.

\section{Considerações finais}

A teoria democrática bobbiana se apresenta como um remédio frente aos males da burocracia e aos temores do "excesso de participação", garantindo a formação de diferentes oligarquias em concorrência entre si, que poderão administrar a sociedade situando-se acima "dos interesses meramente egoístas". Uma democracia mínima, afastada do povo, antagônica ao seu legado originário como sociedade centrípeta, em que o poder estaria nas mãos das classes subalternas, para passar a orientar-se por uma matriz supostamente centrifuga, com múltiplos poderes concorrentes, o que para Bobbio constitui 
a melhor das opções possíveis. Dizemos “supostamente centrífuga” porque, na verdade, se formos analisar seriamente os processos de tomada de decisões nas sociedades capitalistas contemporâneas, verificaremos que há uma crescente concentração política em mãos do que Atilio Boron (2001), adequadamente, chama de "novos leviatãs", as megacorporações transnacionais que na atualidade têm muito mais poder do que muitas nações e estados nos diversos continentes.

É por isso que Bobbio se engana redondamente ao afirmar que, "[q]uando no século passado se manifestou o contraste entre liberais e democratas, a corrente democrática levou a melhor, obtendo gradual mas inexoravelmente a eliminação das discriminações políticas, a concessão do sufrágio universal" (Bobbio, 2006a, p. 96). Na verdade quem "levou a melhor" foi o liberalismo, obtendo um triunfo esmagador contra a democracia. Daí que o que hoje se denomina de regimes democrático-liberais sejam regimes muito mais liberais do que propriamente democráticos.

E Bobbio volta a se enganar quando crê ver apenas nos novos liberais (ou liberistas ou neoliberais) os inimigos da democracia. Novos e velhos liberais, à luz dos fatos históricos, e ao longo de toda sua trajetória, tiveram sempre uma forte animadversão frente ao ideário democrático. O liberalismo só passou a incorporar a expressão democracia a seu léxico bem entrado o século XIX, depois de ter conseguido castrar todo o potencial subversivo que esse conceito carregava, depois de ter domesticado o projeto democrático, desvinculando-o de qualquer significado ligado à emancipação social. Porém Bobbio diz:

No entanto, o estado paternalista de hoje é a criação não do príncipe iluminado, mas dos governos democráticos. Aqui está toda a diferença, e é uma diferença que conta. Uma diferença que conta porque, antes, a doutrina liberal podia ser bem-sucedida ao combater simultaneamente o paternalismo e o absolutismo, e portanto ao fazer caminhar no mesmo passo a emancipação da sociedade civil do poder político (o mercado contra o estado, como se diria hoje) e a instituição do estado representativo (o parlamento contra o monarca). Hoje, porém, esta luta em duas frentes conduziria inevitavelmente ao fim da democracia (e já existem as primeiras escaramuças nesta direção) (Bobbio, 2006b, p. 136).

Trata-se então de saber se é possível voltar ao mercado econômico, como pedem os novos liberais, sem reformar ou até mesmo abolir o mercado político. Se não aboli-lo, limitar-lhe o raio de ação. As propostas políticas destes novos liberais vão todas 
nesta direção, que está na lógica da doutrina clássica dos limites do poder do estado, pouco importando se o poder do estado seja, como é nos regimes democráticos, o poder do povo e não do príncipe (Bobbio, 2006b, p. 138-139).

Insistimos: não há uma diferença substantiva entre velhos e novos liberais (ou liberistas) quando se trata de enfrentar o ideário democrático. Aqui reside o problema da filosofia bobbiana. E aqui está o nó que deve ser desatado por todos aqueles que almejamos uma democracia realmente popular, entendida como autogoverno de mulheres e homens que lutam pela expansão de direitos e liberdades em prol de um futuro melhor. Um projeto, logicamente, que visa terminar com o capitalismo e construir outro tipo de configuração social. Um projeto, em síntese, que, como bem nos lembra Domenico Losurdo (1996), em muitos sentidos deve muito mais àquela tradição política que vai de Robespierre a Lênin, do que àquela que remete a Locke, os Federalistas e Tocqueville.

\section{Referências}

ANDERSON, Perry (1989). "As afinidades de Norberto Bobbio". Novos Estudos, n. 24, p. 14-41.

BOBBIO, Norberto (1955). Política e cultura. Turin: Einaudi..

(1987). "Dall'ideologia democrática agli universali procedurali", em Teoria generale della política. Turin: Einaudi.

(1996). “Democracia”, em SANTILLÁN, José Fernández (coord.). Norberto Bobbio: el filósofo y la política. México: Fondo de Cultura Econômica.

(1997). Né com Marx né contro Marx. Roma: Riuniti.

(1998). Diário de um século: autobiografia. Rio de Janeiro: Campus. (2006a). Liberalismo e democracia. São Paulo: Brasiliense.

(2006b). O futuro da democracia. São Paulo: Paz e Terra.

BOHMAN, James (1996). Public deliberation: pluralism, complexity, and democracy. Cambridge: MIT Press.

BORON, Atilio (2001). “Os novos leviatãs e a polis democrática”, em A coruja de Minerva: mercado contra democracia no capitalismo contemporâneo. Petrópolis: Vozes.

BRANDÃO, Assis (2006). “Bobbio na história das ideias democráticas”. Lua Nova, n. 68, p. 123-145. 
BUDGE, Ian (1993). "Direct democracy: setting appropriate terms of debate", em HELD, David (ed.). Prospects for democracy. Stanford: Stanford University Press.

CROZIER, Michel; HUNTINGTON, Samuel \& WATANUKI, Joji (1975). The crisis of democracy: report on the governability of democracies to the Trilateral Commision. New York: New York University Press.

LOSURDO, Domenico (1996). "Marx, a tradição liberal e a construção histórica do conceito universal de homem”. Educação e Sociedade, v. 17, n. 57 , p. 686-708.

(2004). Democracia ou bonapartismo: triunfo e decadência do sufrágio universal. Rio de Janeiro: Editora da UFRJ, Editora da UNESP. (2006). Contra-história do liberalismo. São Paulo: Idéias \& Letras. LUXEMBURGO, Rosa (1991). A Revolução Russa. Rio de Janeiro: Vozes. MARTINS, Carlos Estevam (2003). "Liberalismo: o direito e o avesso". Dados, n. 46 , p. 619-660.

NEGRI, Antonio (1989). "Review of Bobbio: Future of democracy and Which socialism?”. Capital \& Class, n. 37, p. 156-161.

VITULLO, Gabriel (2007). Teorias da democratização e democracia na Argentina contemporânea. Porto Alegre: Sulina.

(2009). "Representação política e democracia representativa são expressões inseparáveis? Elementos para uma teoria democrática pósrepresentativa e pós-liberal”. Revista Brasileira de Ciência Política, n. 2, p. 271-301.

ZAKARIA, Faared (1997). “The rise of illiberal democracy". Foreign Affairs, v. 76, n. 6 , p. $22-43$.

(2003). The future of freedom: illiberal democracy at home and abroad. New York: W.W. Norton.

\section{Resumo}

Busca-se, neste texto, examinar as relações que se estabelecem entre o liberalismo e a democracia na obra de Norberto Bobbio. A partir de tal exame, procura-se realizar uma interpretação crítica da concepção bobbiana da democracia e das consequências políticas que tal concepção traz atreladas. Espera-se, assim, contribuir para o questionamento da teoria democrática hegemônica, abrindo espaço para outros enfoques.

Palavras-chave: Democracia; liberalismo; Bobbio. 


\begin{abstract}
In this text we want to examine the relationships established between liberalism and democracy in the work of Norberto Bobbio. From this examination, we seek to make a critical interpretation of the Bobbian conception of democracy and political consequences implied by such a conception. We expect to contribute to challenge hegemonic democratic theory, thus opening space for other approaches.
\end{abstract}

Keywords: Democracy; liberalism; Bobbio.

Recebido em 30 de setembro de 2013.

Aprovado em 21 de dezembro de 2013. 